\title{
Effects of Clozapine, Haloperidol, and Fluoxetine on the Reversal of Cocaine-Induced Locomotor Sensitization
}

\author{
Seung Keun Cha ${ }^{1}$ and Ung Gu Kang ${ }^{1,2} \bowtie$ \\ ${ }^{1}$ Department of Neuropsychiatry, Seoul National University Hospital, Seoul, Republic of Korea \\ ${ }^{2}$ Institute of Human Behavioral Medicine, Seoul National University College of Medicine, Seoul, Republic of Korea
}

Objective Repeated treatment with psychostimulants induces sensitization of the dopaminergic system in the brain. Dopaminergic sensitization has been proposed as a mechanism of psychosis. Although antipsychotics block the expression of sensitized behavior, they are ineffective for reversing the sensitized state. We investigated the effect of clozapine, haloperidol, and fluoxetine on the reversal of cocaine-induced behavioral sensitization.

Methods Male ICR mice were sensitized to cocaine with repeated treatment. Animals were then split into four groups, and each group was treated with vehicle or one of the above drugs for 5 days. After a 3-day drug washout, locomotor activity was assessed before and after a cocaine challenge.

Results Clozapine reversed the sensitized state, whereas haloperidol did not. Fluoxetine seemed to reverse the sensitization partially. Conclusion We confirmed that $\mathrm{D}_{2}$ blockade was not effective for reversing sensitization. The reversal by clozapine is partially explained in terms of its strong $5-\mathrm{HT}_{2}$ and weak $\mathrm{D}_{2}$ affinity. The partial reversal by fluoxetine seemed to be related to its serotonin-augmenting action.

Psychiatry Investig 2014;11(4):454-458

Key Words Clozapine, Cocaine, Fluoxetine, Haloperidol, Sensitization.

\section{INTRODUCTION}

Repeated treatment with psychostimulant drugs, such as cocaine or amphetamines, induces enhanced locomotor activity in animals via sensitization of the dopamine system. ${ }^{1,2}$ In humans, chronic intermittent use of amphetamines induces psychosis, which is related to sensitization of the dopamine system. ${ }^{3}$ Dopaminergic sensitization has been proposed as a mechanism of psychosis in general. ${ }^{4,5}$ An abnormally increased dopamine signal induced by the sensitization can lead to abnormally increased salience attribution to otherwise neutral stimuli, which may underlie pathological phenomena such as the idea of references. ${ }^{6}$

The expression of increased locomotor activity in sensitized

Received: July 26, 2013 Revised: December 2, 2013

Accepted: December 9, 2013 Available online: October 20, 2014

$\triangle$ Correspondence: Ung Gu Kang, MD, PhD

Department of Psychiatry and Behavioral Science, Seoul National University College of Medicine, 101 Daehak-ro, Jongno-gu, Seoul 110-744, Republic of Korea

Tel: +82-2-2072-2296, Fax: +82-2-744-7241, E-mail: kangug@plaza.snu.ac.kr

(a) This is an Open Access article distributed under the terms of the Creative Commons Attribution Non-Commercial License (http://creativecommons.org/licenses/bync/3.0) which permits unrestricted non-commercial use, distribution, and reproduction in any medium, provided the original work is properly cited. animals can be blocked by dopamine 2 receptor $\left(\mathrm{D}_{2}\right)$ blocking agents (antipsychotics). Moreover, the same agents can block the development of sensitization when given during the induction period of sensitization. ${ }^{7.8}$ Thus, $\mathrm{D}_{2}$ receptor-mediated dopamine function is mandatory for the development and expression of sensitization. However, once sensitized, $\mathrm{D}_{2}$ blocking agents are not effective in reversing the sensitized state, ${ }^{9}$ with the possible exception of clozapine. ${ }^{10}$ Moreover, antipsychotics themselves can induce dopaminergic sensitization with chronic use. ${ }^{11}$ Previously, we reported a reversal of cocaine-induced sensitization by subchronic use of clozapine. ${ }^{10}$ Although clozapine blocks $\mathrm{D}_{2}$ receptors, it has much higher affinities for serotonergic $5-\mathrm{HT}_{2}$ receptors. In this report, we examined whether this reversal can be achieved by the typical antipsychotic haloperidol, which has a $\mathrm{D}_{2}$-bocking activity without $5-\mathrm{HT}_{2}$ receptor affinity, and the serotonergic antidepressant fluoxetine.

\section{METHODS}

\author{
Animals \\ Thirty-nine male ICR mice (Orient, Seoul, Korea) weighing
}


approximately $20 \mathrm{~g}$ were used. The mice were maintained under a 12/12-h dark/light cycle, and food and water were available ad libitum. All animal procedures were conducted in accordance with NIH Guidelines for the Use of Laboratory Animals. In order to reduce the number of animals, we did not use a separate control group for cocaine-induced sensitization. The mice were given $20 \mathrm{mg} / \mathrm{kg}$ cocaine- $\mathrm{HCl}$ dissolved in $0.9 \% \mathrm{NaCl}$ intraperitoneally (Belgopia, Louvain-LaNeuve, Belgium) for 5 consecutive days. Locomotor activity was measured after the first (day 1) and last (day 5) treatments. Injections on days 2, 3, and 4 were administered in their home cages. One week after the last treatment, another dose of cocaine was given, and locomotor activity was measured to confirm that the sensitized state was maintained (day 13). The animals were then split into four groups based on locomotor activity on that day, in a manner in which the mean activity for each group was similar. Allocation of a specific drug to each group was determined randomly. Drug treatments began 3 days later, and the animals were given clozapine (5 $\mathrm{mg} / \mathrm{kg}$ ), fluoxetine (10 mg/kg), haloperidol (2 mg/kg), or vehicle $(0.3 \%$ tartaric acid, $\mathrm{pH}$ adjusted to 5.0$)$ for 5 consecutive days. After a 3-day washout period, the animals were finally challenged with the same dose of cocaine, and their locomotor activities were measured (day 23) (Figure 1).

\section{Measurement of locomotor activity}

Locomotor activity was measured in a sound-attenuated test room, using a home-cage video tracking apparatus (Activity Monitor Ver. 5.0, MED-Associates, St. Albans, VT, USA). Mice were placed on the test room $3 \mathrm{~h}$ before the test to acclimate the animals to the testing environment. Each animal was placed in a transparent acrylic box $(23 \times 21 \times 21 \mathrm{~cm})$, and its distance traveled was measured for $30 \mathrm{~min}$ in 5 -min time block ('pre-cocaine'). Then, the animal was injected with cocaine $(20 \mathrm{mg} / \mathrm{kg})$ and distance traveled was measured for another $60 \mathrm{~min}$ in the same way ('post-cocaine'). Locomotor ac-

\begin{tabular}{|c|c|c|c|c|c|c|c|}
\hline \multirow[t]{3}{*}{ Time (d) } & $1---5$ & 6------12 & 13 & $14-15$ & 16----20 & $21-22$ & 23 \\
\hline & 4 & 4 & 4 & 4 & 4 & 4 & 4 \\
\hline & 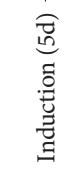 & 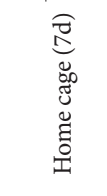 & 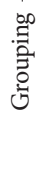 & 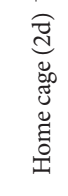 & 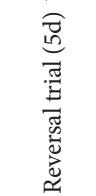 & 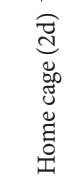 & 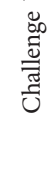 \\
\hline
\end{tabular}

Figure 1. Experimental schedule. Cocaine was administered for 5 consecutive days (days 1-5), and locomotor activity was measured on days 1 and 5 . The maintenance of sensitization was confirmed by a cocaine challenge on day 13 , and animals were grouped according to locomotor activity. Subsequently, clozapine, haloperidol, fluoxetine, or vehicle were administered for 5 days from days 16 to 20 . The final cocaine challenge was performed on day 23. tivity was measured during the light phase of the day (12:0020:00 h).

\section{Statistical analysis}

Data were analyzed using analysis of variance (ANOVA) with post-hoc Duncan's test, or the paired t-test (two-tailed). $\mathrm{P}<0.05$ was statistically significant. The software was SPSS ver 19 (IBM, Armonk, NY, USA).

\section{RESULTS}

\section{Sensitization}

Repeated cocaine treatment for 5 days significantly increased locomotor activity after the cocaine challenge (day 1 vs. day $5, \mathrm{t}=-5.177, \mathrm{df}=38, \mathrm{p}=0.000$, paired $\mathrm{t}$-test). When locomotor activity was measured 1 week later (day 13), this sensitized state was maintained (day 1 vs. day $13, \mathrm{t}=-4.293, \mathrm{df}=38$, $\mathrm{p}=0.000$ ). However, no significant change in locomotor activity was observed during the $30 \mathrm{~min}$ before the cocaine challenge (Figure 2).

\section{Group differences in post-cocaine locomotor activities}

We divided the animals into four groups to maintain similar post-cocaine locomotor activity mean values on day 13 . No group differences in locomotor activity on days $1(\mathrm{~F}=0.224$, $\mathrm{df}=38, \mathrm{p}=0.879$, ANOVA ), 5 ( $\mathrm{F}=0.690, \mathrm{df}=38, \mathrm{p}=0.564)$, or 13 $(\mathrm{F}=0.119, \mathrm{df}=38, \mathrm{p}=0.948)$ were observed. However, we found a significant group difference in post-cocaine locomotor activity on day $23(\mathrm{~F}=2.883, \mathrm{df}=38, \mathrm{p}=0.049)$. The post-hoc test

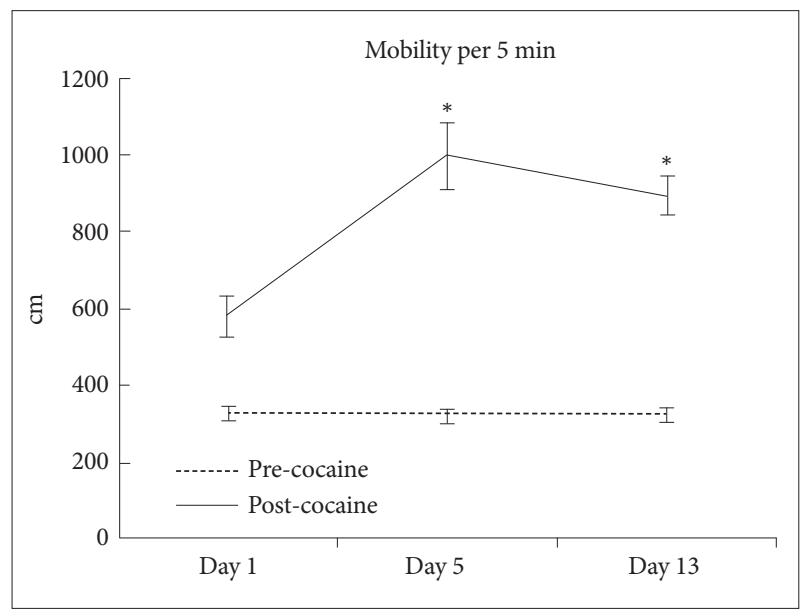

Figure 2. Induction of behavioral sensitization after cocaine treatment. Locomotor activities pre- (for $30 \mathrm{~min}$ ) and post- (for $60 \mathrm{~min}$ ) cocaine administration were measured and the average values were plotted on days 1,5 , and $13(n=39)$. Pre-cocaine activities were not different between days. Post-cocaine activities increased significantly on day 5 , as compared to day 1 , and the increase was maintained until day 13. Error bars represent the standard error of mean. *significant difference compared to day 1 at $p=0.05$. 
discriminated the clozapine group from the vehicle group, while the haloperidol and fluoxetine groups were not discriminated from the vehicle group (Figure 3A).

We also examined changes in post-cocaine locomotor activity on day 23 from day 5 (sensitized) in each group using a paired t-test. The change was significant in the clozapine group $(\mathrm{t}=3.259, \mathrm{df}=9, \mathrm{p}=0.010)$, but not in the fluoxetine $(\mathrm{t}=$ $-0.722, \mathrm{df}=9, \mathrm{p}=0.489)$, haloperidol $(\mathrm{t}=-1.535, \mathrm{df}=9, \mathrm{p}=0.159)$ or vehicle $(\mathrm{t}=0.956, \mathrm{df}=8, \mathrm{p}=0.367)$ groups. This shows that the sensitized state was altered by clozapine (Figure 4A).

\section{Group difference in pre-cocaine locomotor activities}

We also examined the pre-cocaine locomotor activities and found no group differences on days 1, 5, and 13. However, on day 23 , the pre-cocaine activities differed between groups $(\mathrm{F}=$ 3.450, $\mathrm{df}=38, \mathrm{p}=0.027$, ANOVA) (Figure 3B). Post-hoc test discriminated the clozapine and fluoxetine groups from the vehicle group. Further analysis comparing day 23 pre-cocaine activity to day 5 pre-cocaine activity revealed that the activity is not changed in the clozapine $(\mathrm{t}=0.038, \mathrm{df}=9, \mathrm{p}=0.971)$ and fluoxetine $(\mathrm{t}=1.019, \mathrm{df}=9, \mathrm{p}=0.335)$ groups but increased in the haloperidol $(\mathrm{t}=-3.162, \mathrm{df}=9, \mathrm{p}=0.038)$ and vehicle groups $(\mathrm{t}=-2.431, \mathrm{df}=8, \mathrm{p}=0.041)$. Thus the group difference emanated from the increased activity in the haloperidol and vehicle groups (Figure 4B). However the significance disappeared when corrected for the multiple testing.

\section{DISCUSSION}

Although the treatment period of 5-days for both cocaine and therapeutic agents is insufficient from a clinical point of view, our previous results definitely indicated the feasibility of this experimental paradigm, and we used a similar one in the present study. Haloperidol- or vehicle-treated groups showed a trend of increase in the pre-cocaine locomotor activity on day 23 , compared to day 5 . We could not find this effect in our previous experiment. ${ }^{10}$ If we assume that the locomotor activity before cocaine challenge reflects the intrinsic dopamine activity, this difference may be due to the difference in the experimental protocol. In the previous experiment, all cocaine injections were performed in the locomotor chambers, while in the present experiment the 2nd to 4th injections

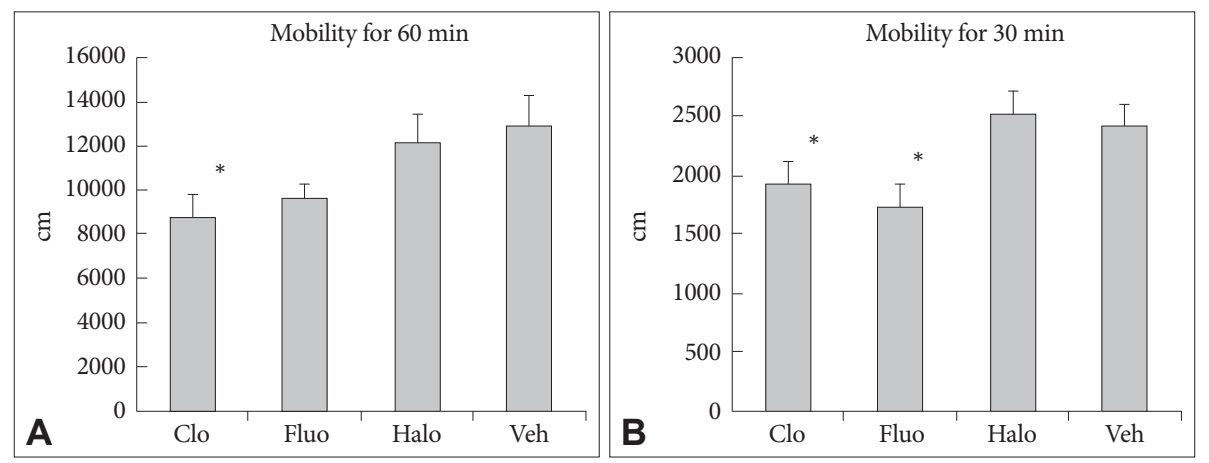

Figure 3. Effects of drugs on sensitized locomotor activity, comparison between drugs (day 23). Locomotor activities, pre- and post-cocaine administration, were measured on day 23 and the total distance for 30 or 60 min was plotted for each treatment group. A: Post-cocaine: Statistical analysis indicated a significant group difference $(F=2.883, p=0.049$, ANOVA). Post-hoc analysis distinguished the clozapine group from the vehicle group. B: Pre-cocaine: Statistical analysis indicated a significant group difference $(F=3.450, p=0.027, A N O V A)$. Post-hoc analysis distinguished the clozapine and fluoxetine groups from the vehicle group. *significant difference compared to the vehicle group at $p=0.05$.
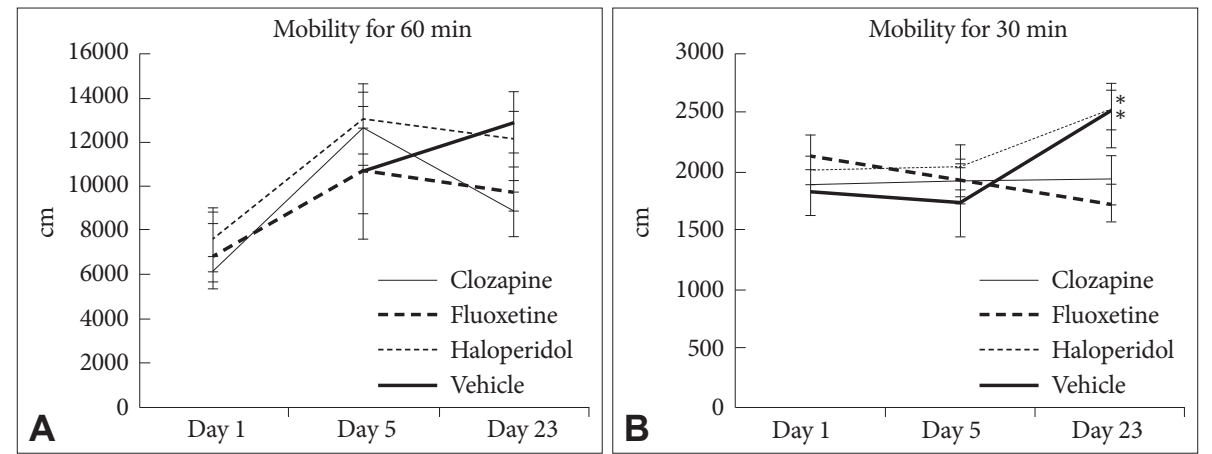

Figure 4. Effects of drugs on sensitized locomotor activity, comparison between pre- and post-treatment. A: Post-cocaine: day 23 stimulated locomotor activity was significantly reduced by clozapine treatment $(\mathrm{t}=3.259, \mathrm{df}=9, \mathrm{p}=0.010)$. B: Pre-cocaine: day 23 baseline locomotor activity was significantly increased by haloperidol $(t=-3.162, d f=9, p=0.038)$ and vehicle $(t=-2.431, d f=8, p=0.041)$ treatments. *significant difference compared to day 5 in each drug at $p=0.05$ (not corrected for multiple testing). 
were performed in the home cages. Thus on day 23 in the present study, the locomotor chambers might still be a "novel" environment or a kind of stress for the animals, and the endogenous dopaminergic activity would be increased. ${ }^{12,13}$ This increased pre-cocaine activity would make the group difference discernable when the sensitization was further advanced by the challenges on days 5 and 13 . Dopaminergic drug haloperidol treatment neither ameliorated nor aggravated the sensitized state in our condition. Fluoxetine, a drug with serotonergic activity, prevented the increase in pre-cocaine locomotor activity. This may be related to the stress-reducing effect of antidepressant or the serotonergic mechanism discussed below.

Although $\mathrm{D}_{2}$ blocking agents can induce depression, a lowdose SDA is indicated in some cases of depression. Ritanserin, a 5- $\mathrm{HT}_{2}$ antagonist, is effective for treating depressive symptoms. ${ }^{14,15}$ In animal models, $5-\mathrm{HT}_{2}$ blockade has a serotoninaugmenting effect, which has been suggested as the mechanism of the antidepressant effect of SDAs. ${ }^{16}$ Thus the SDA and fluoxetine may have common effect in augmenting the serotonergic system and this action without dopamiergic blockade may be related to the partial effect of fluoxetine. Ritanserin partially reversed metamphetamine-induced sensitization. ${ }^{17}$

The present results basically replicated our previous findings regarding clozapine. ${ }^{10}$ We also confirmed that the recovery from the sensitized state was not achieved by the typical antipsychotics haloperidol. The dose of haloperidol used in our study is in a somewhat high range, $2 \mathrm{mg} / \mathrm{kg}$. Many studies use animal select dose in range of $0.2-2 \mathrm{mg} / \mathrm{kg}$. But the locomotor activity of haloperidol applied group was not low high in our study (Figure 3). The sedative effect of high dose haloperidol could be therefore excluded. Moreover, our protocol had a sufficient time for wash-out period in order to exclude an acute drug effect. Although antipsychotics inhibit the induction of sensitization and block expression of sensitization when co-administered with the stimulants, typical antipsychotics per se can induce dopaminergic sensitization when given repeatedly. ${ }^{11}$ Thus the high-dose haloperidol could reinforce cocaine-induced dopaminergic hypersensitivity. In some groups, tardive dyskinesia (TD) is believed to be a consequence of dopaminergic hypersensitivity induced by longterm $\mathrm{D}_{2}$ blockade. ${ }^{18,19}$ However, its effects were only comparable to the vehicle in the present study. Sensitization is reversed by the combination of serotonergic $5-\mathrm{HT}_{2} \mathrm{~A}$ blockade and dopaminergic agonist or stimulant. ${ }^{9}$ Clozapine has much higher affinity for $5-\mathrm{HT}_{2}$ receptors than for $\mathrm{D}_{2}$ receptors. We used low-dose clozapine $(5 \mathrm{mg} / \mathrm{kg})$, which would have sufficient action on 5- $\mathrm{HT}_{2}$ receptors with little effect on $\mathrm{D}_{2}$ receptors. This may be related to the present result as well as to its effects on TD. However, 5- $\mathrm{HT}_{2}$ blockade alone is insufficient to completely reverse the sensitized state and an unknown mechanism may work for clozapine in this regard. The second-generation antipsychotics other than clozapine, with high affinities for both 5- $\mathrm{HT}_{2}$ and $\mathrm{D}_{2}$ receptors (serotonin-dopamine antagonists, SDAs), are ineffective for treating TD or even induce TD 20 and this suggests that even under the 5- $\mathrm{HT}_{2} \mathrm{~A}$ blockade, $\mathrm{D}_{2}$ blockade would not result in the amelioration of sensitized state.

We found that clozapine and fluoxetine had reversal ability of sensitized state, but the underlying mechanism is unclear. Moreover the relationship between biochemical and behavioral changes are unclear, too. Thus, more studies are necessary in view of biochemical perspectives.

\section{Acknowledgments}

This work was supported by a research grant from KT\&G, Republic of Korea.

\section{REFERENCES}

1. Post RM, Rose H. Increasing effects of repetitive cocaine administration in the rat. Nature 1976;260:731-732.

2. Pierce RC, Kalivas PW. Repeated cocaine modifies the mechanism by which amphetamine releases dopamine. J Neurosci 1997;17:3254-3261.

3. Ujike $H$, Sato $M$. Clinical features of sensitization to methamphetamine observed in patients with methamphetamine dependence and psychosis. Ann N Y Acad Sci 2004;1025:279-287.

4. Lieberman JA, Sheitman BB, Kinon BJ. Neurochemical sensitization in the pathophysiology of schizophrenia: deficits and dysfunction in neuronal regulation and plasticity. Neuropsychopharmacology 1997;17: 205-229.

5. Seeman P, Schwarz J, Chen JF, Szechtman H, Perreault M, McKnight GS, et al. Psychosis pathways converge via D2high dopamine receptors. Synapse 2006;60:319-346.

6. Howes OD, Kapur S. The dopamine hypothesis of schizophrenia: version III--the final common pathway. Schizophr Bull 2009;35:549-562.

7. Kuribara H, Uchihashi Y. Effects of dopamine antagonism on methamphetamine sensitization: evaluation by ambulatory activity in mice. Pharmacol Biochem Behav 1994;47:101-106.

8. Meng ZH, Feldpaush DL, Merchant KM. Clozapine and haloperidol block the induction of behavioral sensitization to amphetamine and associated genomic responses in rats. Brain Res Mol Brain Res 1998;61: 39-50.

9. Shuto T, Nishi A. Treatment of the Psychostimulant-Sensitized Animal Model of Schizophrenia. CNS Neurosci Ther 2011;17:133-139.

10. Park HJ, Cui FJ, Hwang JY, Kang UG. Effects of clozapine on behavioral sensitization induced by cocaine. Psychiatry Res 2010;175:165-170.

11. Klinzova AJ, Uranova NA, Haselhorst U, Schenk H. Synaptic plasticity in rat medial prefrontal cortex under chronic haloperidol treatment produced behavioral sensitization. J Hirnforsch 1990;31:175-179.

12. Claustre Y, Rivy JP, Dennis T, Scatton B. Pharmacological studies on stress-induced increase in frontal cortical dopamine metabolism in the rat. J Pharmacol Exp Ther 1986;238:693-700.

13. Hooks MS, Jones GH, Smith AD, Neill DB, Justice JB Jr. Response to novelty predicts the locomotor and nucleus accumbens dopamine response to cocaine. Synapse 1991;9:121-128.

14. Bersani G, Pozzi F, Marini S, Grispini A, Pasini A, Ciani N. 5-HT2 receptor antagonism in dysthymic disorder: a double-blind placebo-controlled study with ritanserin. Acta Psychiatr Scand 1991;83:244-248.

15. Strauss WH, Klieser E. Psychotropic effects of ritanserin, a selective S2 antagonist: an open study. Eur Neuropsychopharmacol 1991;1:101-105. 
16. Blier P, Blondeau C. Neurobiological bases and clinical aspects of the use of aripiprazole in treatment-resistant major depressive disorder. J Affect Disord 2011;128(Suppl 1):S3-S10.

17. Ago Y, Nakamura S, Kajita N, Uda M, Hashimoto H, Baba A, et al. Ritanserin reverses repeated methamphetamine-induced behavioral and neurochemical sensitization in mice. Synapse 2007;61:757-763.

18. Andreassen OA, Jorgensen HA. The rat model of tardive dyskinesia: relationship between vacuous chewing movements and gross motor activity during acute and long-term haloperidol treatment. Life Sci 1995; 57:2263-2272.

19. Casey DE. Tardive dyskinesia: pathophysiology and animal models. J Clin Psychiatry 2000;61(Suppl 4):5-9.

20. Correll CU, Schenk EM. Tardive dyskinesia and new antipsychotics. Curr Opin Psychiatry 2008;21:151-156. 